\title{
Proposing a Holistic Inclusive Education Model for Policy, Curriculum and Classroom Development
}

New Zealand Journal of Teachers' Work, Volume 17, Issue 1 \& 2, 73-87, 2020

\author{
CHRISTOPH TESCHERS (iD https://orcid.org/0000-0002-9543-1772 \\ University of Canterbury
}

\begin{abstract}
The notions of inclusion and diversity are increasingly used in a wide variety of areas in public debate and policy, as well as in educational curriculum and policy documents in New Zealand and internationally since the UNESCO Salamanca Statement in 1994. What is meant by inclusion and diversity in many of these contexts is often rather unclear, however. The discourse of inclusion could be described as often having been taken up uncritically and without reflection on the implications that the use of inclusive language implies. This applies to both educational settings and government policies that use inclusive language to promote inclusion, yet seemingly still operate under a mind-set reflective of mainstream, integration discourse. Although inclusion and inclusive education have been widely discussed in educational literature, the models and frameworks that capture the complexity of inclusive education in theory and practice require further attention. One such model that focuses on five aspects relevant to inclusive education will be introduced in this article, and I will discuss how this model could support policy, curriculum and classroom decision making.
\end{abstract}

\section{TROUBLING INCLUSIVE EDUCATION}

For context, a short historical overview of developments in the discourse of inclusion in education will be provided here, referring to previous discourses of separation, segregation and mainstreaming ${ }^{1}$. These stages and discourses can still be encountered in public debate and educational practice despite the turn to (mostly) inclusive language, as will be outlined below. The development of these discourses has progressed differently in the international context, although some parallels can arguably be seen in many countries to date. I will argue that, despite the development in recent years, issues remain with the concept of inclusive education in theory and practice, some of which I hope to address through the model proposed in this article.

\footnotetext{
${ }^{1}$ Some of the content in this section is based on course material I have written for an introductory course on inclusive education.
} 


\section{Stages of Separation}

Although people with impairments have been treated differently in different cultural settings, the current discourse of disability and inclusion in education is strongly influenced by developments in 'western' cultural contexts and is traced back by Thomas (2013) to the establishment of 'special schools' in the $19^{\text {th }}$ century. This separation process has been intensified "in the early part of the twentieth century by the systemisation of public education and by the simultaneous growth of the eugenic and psychometric movements," which provided a seemingly scientific and "logical foundation for segregative systems" (p. 475). The prevalent point of view was that of a natural distinction between 'normal' and 'handicapped' people, leading to separation in society and education. According to Thomas (2013), the eugenic ideology only evaporated after the Second World War in the middle of the $20^{\text {th }}$ century and "with it the logic for separation" (p. 475).

Despite this progression, the $20^{\text {th }}$ century has seen a significant increase in special schools in many countries, continuing a segregation of people with impairments, with changed intent, however. Whereas earlier special schools were often places in which disabled children were 'kept', school systems were now designed with a more selective special school system in place to support the learning needs of children with impairments more specifically. According to Thomas et al. (2005), "[i]t became received opinion that special schools provide a sensible way of meeting the needs of a minority of children, at the same time as safe-guarding the efficient education of the majority in the mainstream" (p. 18).

\section{Integration and Mainstreaming}

Thomas et al. (2005), however, also state that:

Inclusion is not a new idea. Although recent concern about inclusion can be traced to the civil rights movements of the 1960s, the ideals behind inclusive education have much deeper roots in liberal and progressive thought. If we reach the shaping of the current school system a century earlier, we can see that two avenues were then open. One was inclusive, the other segregative. (p. 17)

Evidently then, considerations of inclusive education (in some respect) had its advocates as far back as the beginning of the $20^{\text {th }}$ century. By the beginning of the $21^{\text {st }}$ century it was, however, being acknowledged that segregation does not provide equality and that all children should be integrated in mainstream schools, the civil rights movements of the 1960s and subsequent developments in the 1970s providing the necessary environment for a shift in thinking to an equal rights perspective. According to Florian (2005), "the task of integration has been about how to join in the mainstream, how to become like others" (p. 30). This expectation of assimilation of everyone into a 'norm', the mainstream, sits quite at odds with current aspirations of valuing diversity in inclusive discourses.

\section{From Integration to Inclusion}

The transition from 'integration' to 'inclusion' can be marked by the Salamanca Statement and Framework for Action (UNESCO, 1994). Although the 
Salamanca Statement itself still uses the terminology of 'special education', the framework also calls for a shift in thinking from integration to inclusion and an 'education for all children'.

The shift in thinking from a deficit discourse driven notion of special education towards inclusive education has seen a range of (sometimes conflicting) interpretations in theory and practice. It was proposed that what is understood under inclusion has to reach beyond integration and mainstreaming, which are still considered to exclude some students to some extent, to achieve real inclusion. Florian (2005) states that the concept of inclusion is more than a name change in terminology, aiming instead to transcend a narrow understanding of 'placement' of children with impairments within mainstream schools towards the idea of inclusion of all children, in their wide range of diversity, in their local school community setting. The literature on the topic of inclusion also acknowledges, however, that, so far, a unified interpretation of 'inclusion' has not been reached. Rather, Clough and Corbett (2000) argue that inclusion is

a contestable term used to different effect by politicians, bureaucrats and academics. 'Inclusion' is not a single movement; it is made up of many strong currents of belief, many different local struggles and a myriad forms of practice. (p. 6)

\section{A social constructive view of inclusive education}

The term special education, which has been commonly in use in the discourses of separation, segregation and integration, is built on a medical understanding of disability as a 'condition' or 'limitation' of a student. This approach connected to the notion of special education has a labelling (if not stigmatising) effect on these students. Inclusive education discourse, in contrast, understands disability as a socially constructed result of an environment that does not cater for the diversity of people in society, and which, therefore, creates barriers through the interchange between persons and environment (Carrington et al., 2016). This discourse regards human diversity as norm instead of promoting an idealised pre-defined common 'norm' that effectively 'others' anyone outside of this norm (e.g. Ballard, 2004; 2013). Coincidental calls for 'inclusive teaching practices' in the current neoliberal climate have contributed to a changed perspective on space (Benade, 2019a), pedagogy, and the relationship between teachers and students. While some of these changes, one could argue, call into question the function of teachers and teaching itself (Biesta, 2013), regarding inclusion in light of the proposed holistic model below, requires that the active role of teachers in the development of students as both learners and as human beings is acknowledged.

So, what is proposed here is a holistic view on inclusive education that aims to clarify what 'inclusive education' means and entails if one follows a broader understanding of 'inclusion' as meaningful participation and belonging (see, for example, Carrington \& MacArthur, 2016, Chapters 1 \& 9). I will argue below which aspects relevant to inclusive educational settings need to be considered. I will also discuss societal implications that result from this shift in social values and thinking, including unreasonable demands (Bowles \& Gintis, 2002) that schooling should bear the main responsibility for social change 
towards equity and an inclusive society. The intention is not to provide clear guidelines for what to do in a particular setting, but to provide a framework for thinking through most (if not all) relevant aspects that contribute to creating an inclusive environment for all children. As such, all of the spheres of the model proposed below need to be considered in each context anew to create localised and contextual practical solutions for an inclusive education approach.

\section{Why another model of inclusive education?}

As indicated above, a range of challenges exist with the current discourse of inclusive education or inclusion in education. As argued elsewhere (Teschers \& McMenamin, 2019), the terminology of diversity and inclusion are in themselves not without challenge, and especially not in the way they are often applied in policy and practice. In Teschers and McMenamin (2019), it is argued that 'diversity' is often used synonymously to 'difference' and categories of diversity in use imply that people/students of 'diversity' are different from a 'norm' (whatever the norm might be). The term 'inclusion', for that matter, implies that someone has to be included into something. What this 'something' is, is again defined by society and arguably constitutes the social and cultural norm of the dominant class in any society. We have, however, argued that one way of potentially overcoming these challenges is to approach diversity from the viewpoint of each person being a unique human being and, therefore, seeing diversity as the norm (2019). This view of diversity and the uniqueness of each individual underpins the holistic approach to inclusive education that is proposed in this article.

Following the transition from the integration to the inclusion discourse above, inclusion can be described as the shift from a shared space to the meaningful participation and belonging of people with diverse abilities and characteristics (Carrington et al., 2016). This can be meaningful participation and belonging in school and other educational settings, as well as in society, politics and democracy (Ballard, 2013). This distinction between schooling and society is made explicit here, as it will be argued later on that calls for a shift towards more inclusion in education cannot be separated from the development of a more inclusive society at large. This links to the historic conflict between voices that call for education to be the motor of change towards a more just society and voices, supported by evidence (Bowles \& Gintis, 2002), that show that schools generally reproduce the status quo in society, and potentially even increase inequities in society.

To understand these seemingly opposing views on what 'education' can achieve, it is important to be aware of the multiple meanings that are attached to this term in academic, public and political discourse. Education, as has been discussed elsewhere (Teschers, 2018), can be understood in at least three different ways: (i) education as knowledge, understanding and self-cultivation (which also relates to the German notion of Bildung); (ii) education as the education system, which I will mostly call schooling in this article; and (iii) education as the reciprocal process of teaching and learning, which relates to pedagogy. These are related, but also somewhat distinct aspects of the term 'education' dependent on context, and I would argue that some of the misconceptions of expectations concerning what education, schooling and teachers are supposedly able to do result from unclear boundaries in the use of the term 'education'. 
'Inclusive education' as a concept is mostly located in the schooling setting, including early childhood, and sometimes tertiary contexts. Seeing schooling as the main setting for inclusion raises a range of questions, however, and maybe a broader view needs to be adopted to children's learning and development in an inclusive manner. Another challenge is the actual pedagogy, the 'how' of teaching and learning, in this and other settings that needs to be considered. One point of critique voiced in the literature is the disjunction of theory and practice (at least in the New Zealand, but likely the international context as well) which often sees pedagogies and procedures in place that are still more reflective of the discourse of integration and mainstreaming, rather than inclusion. I will now turn to the holistic inclusive model which I propose as a framework to think through and address the divide between aspirations and reality in curriculum, policy and practice, and to address some of the challenges of inclusion in education as outlined above.

\section{A HOLISTIC INCLUSIVE EDUCATION MODEL}

Systematic approaches to thinking about, understanding and enacting inclusion in educational settings are few, despite arguments profiling a general understanding of inclusion in education (e.g. Alton-Lee, 2003; Ballard, 2004; 2013; Carrington \& Macarthur, 2016), or diversity in education discourses. The Universal Design for Learning (UDL) (Gordon, Meyer \& Rose, 2014) is one example of structuring classroom practice towards inclusive practices more broadly, and Booth and Ainscow's (2011) Index for Inclusion is a well-researched and widely used approach to strengthening inclusive school cultures. Both approaches focus, however, on schools/centres and/or classrooms and are arguably limited in taking into account each student's life-wide and life-long circumstances. Hence, here I wish to introduce a model, based on a broader understanding of 'education', that takes a student centred, systematic approach to inclusive education. Of interest here is the German understanding of education, which transcends school boundaries, focussing on the concepts Erziehung (upbringing) and Bildung (self-cultivation). While the latter may be better known by readers, both will be explained below, as they inform the holistic education model to be presented here. While the model will be discussed in general terms, so as not to detract from the broader perspective being presented in this article, some examples will be provided that relate to Aotearoa New Zealand, to illustrate points in context.

As indicated above and in Fig. 1 (below), the holistic inclusive education model presented here is comprised of five spheres or areas of consideration: 1) a holistic view of education, 2) a whole-child approach, 3) a whole-school approach, 4) a community approach, and 5) a systems approach. As a holistic approach, these areas cannot be seen as distinct from each other but interact with and impact on each other and together inform the understanding of inclusive education I want to portray here. 


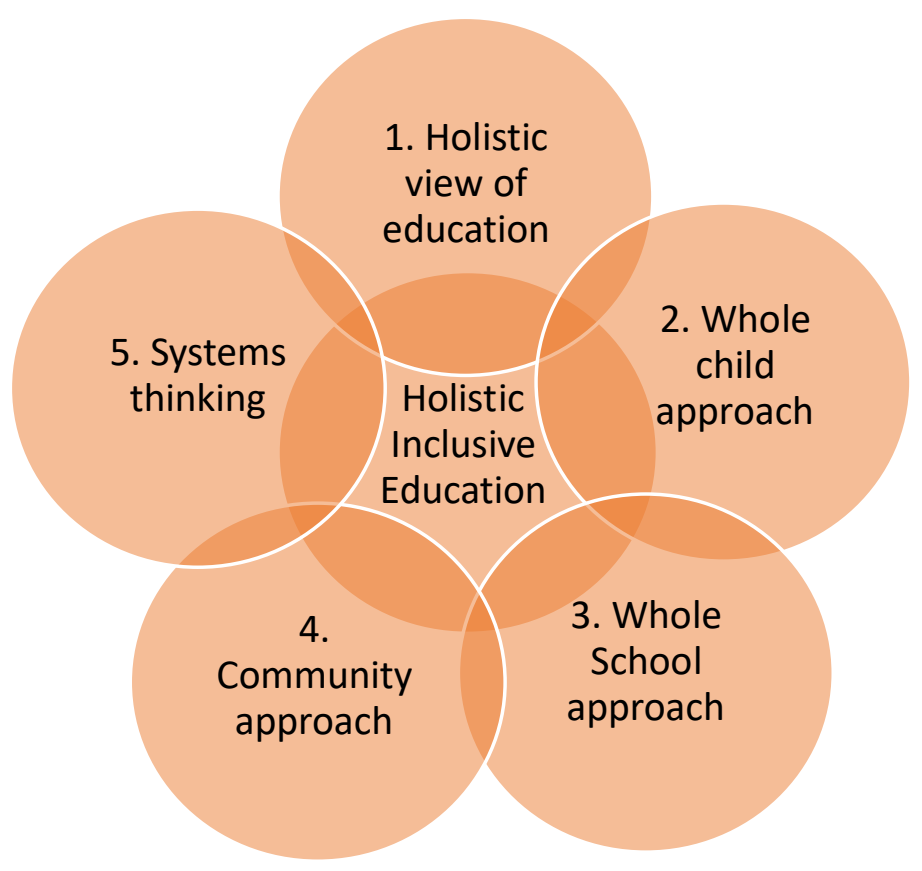

Fig. 1: The five spheres of the holistic inclusive education model

Some of these areas may seem more relevant than others, depending on whether one approaches inclusive education from a policy, a curriculum development or a classroom/pedagogy perspective. I argue, however, that all spheres listed here have some relevance for all aspects of educational policy, curriculum and practice. In what follows, I will describe each sphere of the proposed model, explore some connections between the spheres, and briefly indicate the possible impact on and/or application to curriculum, policy and classroom practice.

\section{Sphere 1 - A holistic view of education}

In common Anglo-American usage, 'education' is used synonymously with schooling and the education system, which, in New Zealand includes early childhood education. By contrast, Erziehung, is a wider conception of education. It includes the home environment, i.e. parents and wider family, and some argue includes anyone contributing to the ongoing socialisation of a young person, such as peers, teachers, sport coaches, youth workers, and religious ministers (e.g. Liebau, 1999). Bildung is often understood as a life-long process of selfcultivation and self-formation that includes a personal refinement through arts, knowledge and cultural practices. This process is strongly assisted through schooling and the education system in the first two decades of a person's life; however, schooling is not the only contributing factor to this process and as mentioned, Bildung is a life-long process beyond one's schooling years. A third notion that Liebau attributes to the German understanding of education is the notion of Entfaltung (flourishing), which one could argue to be an aim of education-enabling each individual to flourish in their own way.

Applying this view to inclusion and considering education as a life-long process of self-cultivation, self-formation and flourishing, I would argue that we need to look beyond schooling and the education system if we want to be inclusive in this process. Inclusive education understood in this way is not limited 
to inclusion in the classroom, and maybe the wider school setting, but considers the opportunities that arise from each person's wider social context for their ongoing education, development and flourishing. This would allow them to participate meaningfully not just in school but as a valued member of their community and society (this also links to Sphere 5).

This view can then largely redefine how educational politics and policies are considered, while bringing into question how the wider context is considered in educational systems today. It also influences the development of curriculum, as connections to the local context of students could be more strongly integrated in curriculum considerations, which is already recommended by some to strengthen student engagement and inclusive practices (e.g. Macfarlane et al., 2012; Pennetito, 2009). One could further ask the question how important learning areas from the curriculum could be supported outside of schools, such as practica or internships. This links clearly to pedagogy and classroom practice which would be called on to more strongly consider and draw on the knowledge and resources of the wider community (links to the Sphere 4) to support students in their learning.

\section{Sphere 2 - A whole child approach}

It has been argued that it is important to consider students more holistically to support their learning and development in school and beyond (de Souza, 2009; Durie, 2001; Macfarlane et al., 2012). Considering each student/child from a lifewide perspective, including their cultural and family background, their socioeconomic status, their language, their experiences, skills and abilities (links to Sphere 5), but also taking a life-long perspective, including their interests, desires and aspirations in life, will provide a much more holistic picture of each student as a person rather than a standardised view of each student as a 'norm' learner. The diversity that comes to the fore here shows the uniqueness of each individual which requires a broad understanding of diversity as the norm for inclusion and not a narrow picture of some deviating from a predetermined norm of 'average human being'.

Unquestionably, taking such an approach will be challenging and timeintensive for teachers who are often already stretched to their limits. Therefore, it is important to consider policy and staffing questions if the aim is to create an inclusive education system. Support and information can, however, also be gained from students' families, peers and local communities (links to the Spheres 1 \& 4), while whole-school approaches (Sphere 3) can act synergistically to reduce some of the workload and expectations from individual classroom teachers. Team teaching and sharing of information within teams also reduce workload and provide a more rounded understanding of each student for all teachers. Some implications of taking into account the uniqueness of each student for the classroom would also be to utilise a universal design for learning framework in lesson and task planning, allowing for different levels of engagement but also responding to different student interests to ensure tasks and content remain relevant to students. This situation is one that is already realised in many innovative settings (Alterator \& Deed, 2018; Benade, 2019b), and is thus not a bridge too far.

Such an approach also resonates with Schmid's (2000) art of living approach and my (Teschers, 2018) adaptation of Schmid's work towards an education for life that focuses on developing students' own art of living. I have 
argued that an aim of education should always be to support students to live a good and beautiful life based on their own norms, values and beliefs, and linked to their personal interests and aspirations (Teschers, 2018). Curriculum content that is relevant to students' lived experience, their interests and aspirations is not only motivating, but supports students to see the relevance of academic knowledge for their own life pathways and to discern interconnectedness in what may otherwise seem disjointed. Interconnected curriculum content can create a holistic, 'big picture' view of the world for students. In the New Zealand context, this approach also resonates well with the Effective Pedagogy recommendations and the School Curriculum design recommendation of using overarching themes and organising learning across apparent boundaries as outlined in the New Zealand Curriculum (Ministry of Education, 2007).

\section{Sphere 3 - A whole school/centre approach}

From a holistic perspective, inclusion limited to a single classroom setting seems contradictory in itself. Booth and Ainscow (2011) have argued well the relevance of taking a whole school approach to inclusive education through a culture of inclusion, inclusive policies and practices. Expanding on their argument, I would suggest that taking a whole school inclusive approach from a holistic perspective does not stop at considering inclusion for students but looks at an inclusive environment for all members of the school community: students, teachers, principal, administrators, cleaning staff, garden and property staff, parents, and local community. In a New Zealand context, a close connection between school and local community is highly desirable from a kaupapa Māori (indigenous) perspective (Savage et al., 2014). It has been shown, however, that close connections between schools and local communities are beneficial for students in general (Sheldon, 2007), as will be discussed further below in Sphere 4.

The benefit of implementing a practice or culture in a system wide approach for inclusive practices is echoed by Carrington et al. (2016) who not only promote the school wide approach taken by Booth and Ainscow in the Index for inclusion but also point out the supportive aspects for teachers gained from "communities of practice and professional collaborative practices" (p. 352). They draw on Wenger, Beatty and others to argue that teachers are not only supported in their practice through a collaborative approach but also in their own professional development. A community of practice as in a collaborative school wide approach to inclusive education can strengthen teachers' understanding and practice of inclusive education, support their efforts through a wider system and network of inclusive practices and policies, and can have a motivating effect for others in the school community to take the next step in their practice towards strengthening inclusion. Similar synergistic effects of school wide approaches have been commented on in other areas, such as the School Wide Positive Behaviour for Learning approach (Mclntosh et al., 2010).

Implications of this Sphere would sit foremost on a policy level to ensure schools and centres adopt a school/centre wide approach, for example, through utilising the Index for Inclusion. The ripple effect for classroom practice would be a more systemic approach to inclusive practice, supporting individual teachers in their practice and balancing workload through an inclusive culture that is fostered across the school and does not have to be cultivated by individual teachers alone. Similarly, curriculum could be designed with a whole school approach in mind 
that creates links between subject areas and incorporates inclusive language and concepts throughout all curriculum areas consistently, using consistent language.

\section{Sphere 4 - A community approach}

This sphere includes multiple perspectives. As with the whole school/centre approach, limiting inclusive thinking and aspirations to schools and the education system in the hope that this will solve all issues of inequality and exclusion in society is naïve. Inclusion has to be thought about from a society perspective. As mentioned before and explained by Bowles and Gintis (2002), schools are always embedded in and limited by the social structures they are operating under and generally reproduce existing inequalities and exclusions that exist in the wider society. Therefore, realising inclusive environments in schools requires inclusive social structures in society. Bowles and Gintis argue, however, that schools are unlikely to change the status quo in societies due to the societal constrains they are working in. However, the notion that education is the key to challenge and address inequality in society is not unreasonable. Education, however, has to be understood here in the meaning of Bildung: knowledge, understanding, and artful self-cultivation, which includes an ethical component of practical wisdom. For inclusion in educational settings, this requires taking a broader systematic approach to community and society involvement: the transformation towards an inclusive society (see also Sphere 5).

The other perspective that is relevant for a community approach in a schooling context is the inclusion of family and whānau (an indigenous Māori concept relating to ones extended family) and the local community to inform good pedagogy and inclusive practice. Following the evidence-based practice (EBP) model in education of Bourke et al. (2005), good pedagogy needs to be founded in: (i) research evidence; (ii) practitioner knowledge and experience about the local context; and (iii) evidence and knowledge provided by the student and their family. As these authors argue, it is usually the child themselves and their immediate family, mostly the parents, who have the most knowledge and understanding of a child's abilities, needs and interests. Taking an evidencebased approach to practice that includes these three circles of evidence is likely to create a more inclusive environment for children through bonding and belonging as well as consideration of their unique situation. In the New Zealand context, Sonja Macfarlane (in Savage et al., 2014) advocates moderation of this EBP approach through the lenses of tika (right; correct), pono (integrity; fairness) and aroha (care; compassion) to adapt it to the Māori cultural context, similarly emphasising the role of family and whānau as part of evidence supporting good inclusive practice.

A final aspect of community involvement includes local expertise as part of the curriculum and pedagogy. Instead of teaching students about something, why not get students to experience what is on offer in the local community? In addition to the general benefits of experience education (see, for example, Dewey, 1938/2001), this approach can (i) create stronger ties to and integration of the school into the local community; (ii) support exposure to and acceptance of diverse students with members of the community; (iii) create a meaningful place-based connection for the students to the curriculum matter (Penetito, 2009); (iv) and arguably foster a more inclusive environment for students in school and the community. This also links well with other holistic approaches in 
education, such as an education towards an art of living (Schmid, 2000; Teschers, 2018), as referred to before.

\section{Sphere 5 - A systems thinking approach}

Interwoven into most of the spheres of this model is a systems approach based on Bronfenbrenner's (1979/1996) ecological systems theory. Bronfenbrenner considers the student/child/person as an individual surrounded by multiple layers of systems (a microsystem such as family, an exosystem such as social services, and a macrosystem including cultural values and norms) that influence their development and learning. What I want to highlight in this context is not so much the various systems that affect a person, but to draw attention to the fact that systems are at play that strongly affect how inclusion is understood, described, prescribed and enacted-in schools specifically and in society in general. Therefore, what I alert to are two sides of what I see as the same coin: the impact of systems on the development of the individual (Bronfenbrenner), and the impact of systems on inclusion in education.

Leaving the explanation of the earlier point to Bronfenbrenner, I would like to draw attention to some of the systems that affect inclusion in education. Children and individuals comprise the first factor, including their ability and willingness to share and take steps to support an inclusive environment for themselves and others. Similarly, the ability and preparedness of the family, whānau (extended family), peers, as well as teachers and principals, play a role on how inclusion is enacted in local settings, which is influenced, among others, by the social and cultural background of each party. Beyond that, governing bodies come to mind, which can be the board of trustees of a school as in the New Zealand system, or local education hubs or local government regulations and authorities. National curricula and educational policies play a role, as does the political climate towards inclusion and equity on a national level. This also includes the provision for initial teacher education and how inclusive practices are addressed and modelled for new teachers. All of these are impacted by society's (dominant) cultural norms and values. Furthermore, at a global level, international conventions, such as the UNESCO Salamanca Statement, the UN Declaration on the Rights of Disabled Persons, or the UN Declaration of the Rights of the Child, must be considered. Other global factors, such as the ubiquity of the digital economy and large scale forced and voluntary migrations will be additional influences on national decision-making, ultimately filtering to the local school and classroom context.

\section{The holistic inclusive education model extended}

Drawing on the points made about each of the five spheres relevant to a holistic perspective on inclusive education, the extended graphic in Fig. 2 below shows the complexity of the holistic inclusive education model proposed in this article. As indicated before, the proposed model will not be comprehensive and will never provide a complete picture of all aspects involved due to the 'messiness' and changing nature of human life and experience, and the fluidity of societies in our changing world. Indeed, it is intended to emphasise this complexity and help to prevent reliance on often narrow perspectives of so called 'best practices' in educational contexts. 


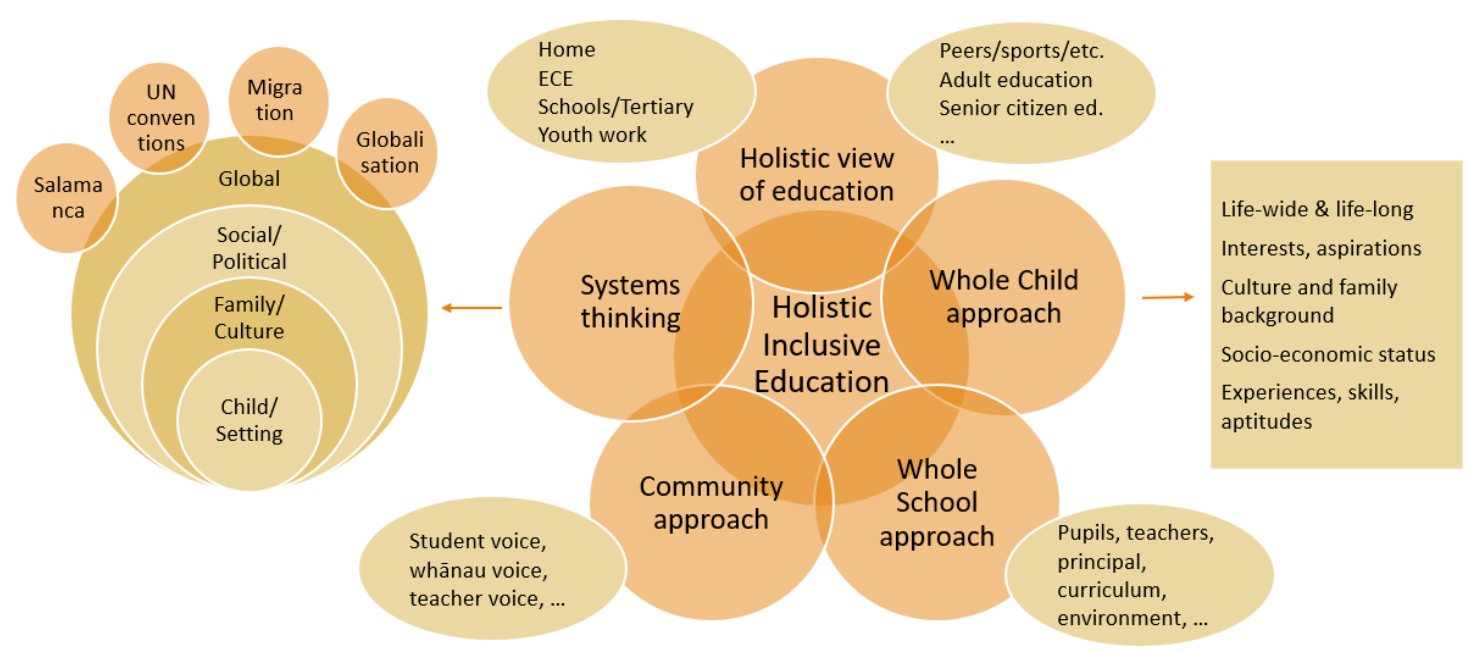

Fig. 2: The Holistic Inclusive Education Model.

As Weick (1984) argued, attempts to find simple solutions for complex problems can lead to frustration. Adopting Weick's approach of 'small wins', the broad and holistic perspective presented here is not deterred by daunting complexities in its effort to ensure inclusive practices in the classroom. Instead, my intention is for policy makers, curriculum developers, school leaders, classroom teachers, parents and students to take small steps to improve inclusive practices and environments in their respective contexts. Despite the challenge, the steady removal of exclusion wherever it occurs, can support the movement of society towards the vision of a fully inclusive environment. This approach can support relevant contextual action that takes account of existing complexities and focuses on aspects most likely to achieve influence at any given point in time.

In practice, this encourages classroom teachers to consider each of their students from a whole-child perspective, taking into account their life-wide circumstances they bring with them, but also their life-long perspective of interests and aspirations for their personal future. Including the local community and acknowledging the role of whanau, and developing relevant place-based curriculum and pedagogy, will create and increase a sense of belonging for each student in the classroom. Holistic views on education can play a role, as might a whole-school perspective if supported by others in the school. Similarly, awareness of the wider systems influencing a teacher's pedagogy and classroom practices can help self-reflective processes, the refinement of a teacher's professional identity and support evidence-based practice.

From a curriculum perspective, the whole child, whole school and community aspects of this model seem most relevant. Depending on the level of curriculum development (i.e. national, local/school, subject classroom), systems considerations and a holistic approach to education can play a role to inform curriculum further. As policymaking is generally a higher-level task, I would argue that all spheres of this holistic approach to inclusive education model should be taken into account for policies in national but also local contexts. The relationship between these spheres and the relevance of each for the different contexts relevant to education are tasks for future research. 


\section{CONCLUSION}

What I have presented here builds on the work of many who have contributed to the overall concept, understanding and application of inclusion in education. What I hope to have added to the discussion is an integrated and higher-level consideration of inclusive education-a meta-framework that takes a holistic perspective and aims to draw attention to the complexity in which inclusion in education has to be considered.

Schools are always embedded in wider social and cultural structures and creating inclusive school environments requires simultaneous work on creating a more inclusive society. The broader issues of inequality and exclusion in society will not be achieved by schools and teachers alone, however. The holistic inclusive education model presented here is intended to support the larger effort that is required.

Manuscript Submitted: March 31, 2020

Manuscript Revised: August 20, 2020

Manuscript Accepted: November 19, 2020 


\section{REFERENCES}

Ainscow, M., Dyson, A., Goldrick, S., \& West, M. (2012). Making schools effective for all: rethinking the task. School Leadership \& Management: Formerly School Organisation, 32(3), 197-213. https://doi.org/10.1080/13632434.2012.669648

Alterator, S. \& Deed, C. (Eds.). (2018). School space and its occupation. Brill.

Alton-Lee, A. (2003). Quality teaching for diverse students in schooling: Best evidence synthesis. Ministry of Education

Ballard, K. (2004). Children and disability: special or included? Waikato Journal of Education, 10, 315-326.

Ballard, K (2013). Thinking in another way: ideas for sustainable inclusion. International Journal of Inclusive Education, 17(8), 762-775. https://doi.org/10.1080/13603116.2011.602527

Benade, L. (2019a). Flexible learning spaces: Inclusive by design? New Zealand Journal of Educational Studies, 54, 53-68. https://doi.org/10.1007/s40841019-00127-2

Benade, L. (2019b). Pedagogy in flexible learning spaces. In M. Hill and M. Thrupp. The professional practice of teaching in New Zealand (6th ed), pp. 213-235. Cengage

Biesta, G. (2013). The beautiful risk of education. Paradigm.

Booth, T., \& Ainscow, M. (2011). Index for Inclusion: developing learning and participation in schools. CSIE.

Bowles, S., \& Gintis, H. (2002). Schooling in Capitalist America Revisited. Sociology of Education, 75(1), 1-18. https://doi.org/10.2307/3090251

Bronfenbrenner, U. (1979/1996). The ecology of human development: experiments by nature and design. Harvard University Press.

Bourke, R., Holden, B., \& Curzon, J. (2005). Using evidence to challenge practice: A discussion paper. Ministry of Education.

Carrington, S. \& MacArthur, J. (2016). Teaching in Inclusive School Communities. Wiley \& Sons.

Carrington, S., Bourke, R., \& Dharan, V. (2016). Using the Index for Inclusion to develop inclusive school communities. In Carrington, S. \& MacArthur, J. (eds) Teaching in Inclusive School Communities. Wiley \& Sons.

Carrington, S., MacArthur, J., Kearney, A., Kimber, M., Mercer, L., Morton, M., \& Rutherford, G. (2016). Towards and inclusive education for all. In Carrington, S. \& MacArthur, J. (eds) Teaching in Inclusive School Communities. Wiley \& Sons.

Clough, P. \& Corbett, J. (2000). Theories of Inclusive Education. Paul Chapman.

De Souza, M. (2009). Promoting wholeness and wellbeing in education: Exploring aspects of the spiritual dimension. In M. de Souza et al. (ed.), International handbook of education for spirituality, care and wellbeing. Springer Science + Business Media.

Dewey, J. (1938/2001). Experience and education. Collier.

Durie, M. (2001). Mauri ora: the dynamics of Māori health. Oxford University Press.

Florian, L. (2005). Inclusive Practice - What, why and how? In Topping, K. \& Maloney, S. (eds.) The RoutledgeFalmer Reader in Inclusive Education. Routledge. 
Gordon, D., Meyer, A., \& Rose, D. (2014). Universal Design for Learning: Theory and practice. CAST professional Publishing.

Liebau, E. (1999). Erfahrung und Veranterwortung: Werteerziehung als Pädagogik der Tailhabe. [Experience and Responsibility: Values education as a pedagogy of participation]. Juventa.

Macfarlane, A., Macfarlane, S., Savage, C., \& Glynn, T. (2012). Inclusive education and Māori communities in Aotearoa New Zealand. In Carrington \& MacArthur (eds.) Teaching in inclusive School Communities. Wiley \& Sons.

McIntosh, K., Filter, K. J., Bennett, J. L., Ryan, C., \& Sugai, G. (2010). Principles of sustainable prevention: Designing scale-up of school-wide positive behavior support to promote durable systems. Psychology in the Schools, 47(1), 5-21. https://doi.org/10.1002/pits.20448

Ministry of Education (2007). The New Zealand Curriculum. Learning Media Limited.

Pennetito, W. (2009). Place-based education: Catering for curriculum, culture and community. New Zealand Annual Review of Education, 18, 5-29.

Savage, C., Macfarlane, S., Macfarlane, A., Fickel, L., \& Te Hēmi, H. (2014). Huakina Mai: A kaupapa Māori approach to relationship and behaviour support. The Australian Journal of Indigenous Education, 43(2), 165-174. https://doi.org10.1017/jie.2014.23

Schmid, W. (2000). Philosophie der Lebenskunst. Eine Grundlegung. [Philosophy of the art of living. A foundation.] Suhrkamp.

Sheldon, S. B. (2007). Improving student attendance with school, family and community partnerships. The Journal of Educational Research, 100(5), 267275. https://doi.org/10.3200/joer.100.5.267-275

Teschers, C. (2018). Education and Schmid's art of living. Routledge.

Teschers, C. \& McMenamin, T. (2019). Diversity within Aotearoa and the New Zealand education system, in Kamp, A. (ed.) Education studies in Aotearoa: Key disciplines and emerging directions. NZCER

Thomas, G. (2013). A review of thinking and research about inclusive education policy, with suggestions for a new kind of inclusive thinking. British Educational Research Journal, 39(3), 473-490. https://doi.org/10.1080/01411926.2011.652070

Thomas, G., Walker, D., \& Webb, J. (2005). Inclusive Practice - The ideals and the practice. In Topping, K. \& Maloney, S. (eds.) The RoutledgeFalmer Reader in Inclusive Edcuation. Routledge.

UNESCO (1994). The Salamanca Statement and Framework for Action on special needs education.

Weick, K. (1984). Small Wins. Redefining the scale of social problems. American Psychology, 39(1), 40-49. https://doi.org/10.1037/0003-066X.39.1.40 
ABOUT THE AUTHOR

CHRISTOPH TESCHERS

University of Canterbury

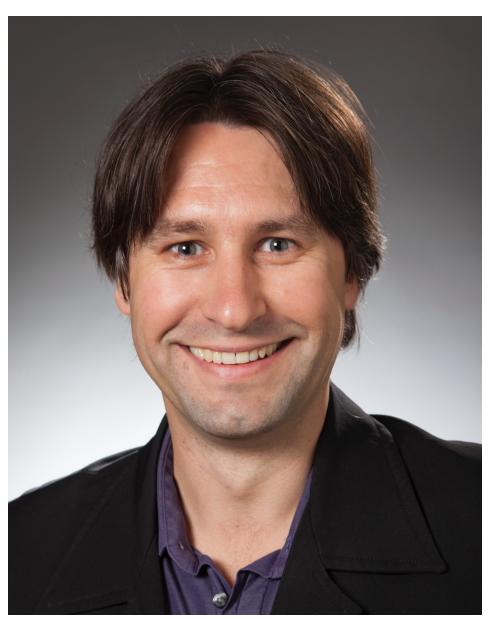

Dr Christoph Teschers is Senior Lecturer at the School of Educational Studies and Leadership, University of Canterbury, New Zealand. He has published several articles and book chapters and is author of Education and Schmid's Art of Living (2018). Taking an interdisciplinary approach, he is mainly interested in the relationship between people's wellbeing, the philosophical notion of the art of living and educational theory and practice. Other areas of interest include philosophy for children, positive psychology, inclusive education, ethics and social justice. christoph.teschers@canterbury.ac.nz 